\title{
EJPPS
}

促

PARENTERAL AND

PHARMACEUTICAL SCIENCES

EJPPS - European Journal of Parenteral and Pharmaceutical Sciences Volume 25 Issue 4

https://www.ejpps.online/effectivereusablecleanroomgarments

https://doi.org/10.37521/ejpps.25401

\section{Effective Re-usable Cleanroom Garments and Evaluation of Garment Life}

T Eaton AstraZeneca, Macclesfield, UK

W Whyte James Watt Building South, University of Glasgow, UK

Corresponding Author: Tim Eaton, Sterile Manufacturing Specialist

AstraZeneca,

UK Operations,

Silk Road Business Park

Macclesfield

Cheshire. SK10 2NA

England

Email: tim.eaton@astrazeneca.com

Telephone: $+44(0) 1625514916$ 


\title{
Effective Re-usable Cleanroom Garments and Evaluation of Garment Life
}

\author{
T Eaton, AstraZeneca, Macclesfield, UK \& W Whyte, James Watt Building South, University of Glasgow, UK
}

\section{Summary}

Cleanroom garments are used to control the airborne dispersion of contamination from people into the cleanroom. The effectiveness of the garment in controlling the dispersion of contamination is a function of the fabric and design of garments, and test methods used to ascertain the effectiveness of garments are discussed in this article. These test methods can be used when choosing garments for use in a cleanroom but were used in this article to determine the deterioration of garments through use. Cleanroom garments were subjected to increasing numbers of decontamination cycles, which included sterilisation by gamma radiation, up to a maximum of 70 . At defined number of decontamination cycles, the garment's fabric was compared to a new fabric by visual examination, by a scanning electron microscope, and by physical tests of key performance parameters. It was concluded that the performance of the fabric remained acceptable up to 50 decontamination cycles. This conclusion was supported by the low dispersion rate of particles and microbe-carrying particles in a dispersal chamber from personnel wearing the garments. After 50 decontamination cycles, a low dispersion rate of $0.2 / \mathrm{s}$ of microbe-carrying particles from personnel wearing the garments was obtained and a 194-fold reduction in the microbial dispersion rate compared to cleanroom undergarments.

Key words: cleanroom garments, garment life, contamination control

\section{Introduction}

Cleanroom garments are a key contamination control method used to limit the transfer of particles from personnel into the surrounding environment. A proportion of these particles are microbe carrying particles (MCPs), and for pharmaceutical and healthcare cleanrooms, they present a risk that must be managed. Garments may be single use or reusable and both have the same contamination control requirements. Single use garments are typically used in situations where contamination can occur from harmful biological, chemical, or radioactive substances, or where low numbers of cleanroom garments are required. Following a single use, they are simply disposed. Re-usable garments are used many times, and between uses are subjected to decontamination cycles, which normally consist of controlled washing, drying, packaging and where appropriate, sterilisation. These decontamination cycles should not significantly reduce the contamination control properties of the garment through its life.

Whyte and Bailey ${ }^{1,2}$ developed tests for assessing the contamination control properties of cleanroom garments and drew attention to the deterioration of garments during use. They also noted that heavily calandered garments lose their effectiveness much more quickly than lightly calandered garments. Ljungqvist and Reinmuller ${ }^{3}$, and Romano et al ${ }^{4}$, used a dispersal chamber to measure the dispersion rate of airborne contamination from personnel wearing clothing that had been subjected to different numbers of decontamination cycles. They found that the effectiveness of garments reduced during use but was acceptable up to about 50 decontamination cycles. Ljungqvist and Reinmuller ${ }^{5}$ further investigated garments using a combination of fabric test methods and dispersal chamber results and confirmed their previous conclusions.

Different fabrics used to manufacture cleanroom garments deteriorate at different rates and we were interested in studying a fabric that had not been previously investigated but appeared to be very effective in reducing the dispersion of airborne contamination. We also wished to study the deterioration of a fabric with tests that included appearance to the eye and use of an electron microscope, as well as studying the deterioration of fabrics over time in more detail.

\section{Requirements for Cleanroom Garments}

Information relating to selection, specification, maintenance, and testing of garments for use in various types of cleanrooms is readily available 6 , 7. For pharmaceutical and healthcare cleanroom applications, there are a number of essential and desirable requirements that need to be considered, and these are summarised in Table 1. Other parameters, such as flame retardancy, chemical resistance, waterproofness, water repellency, and anti-microbial surface properties, may be required for certain applications. The requirements that the authors consider to be the most important are included in Table 1.

Table 1 Requirements for effective cleanroom garments

\begin{tabular}{|c|c|c|}
\hline Consideration & Requirements & Comments \\
\hline $\begin{array}{l}\text { 1. Barrier to } \\
\text { particles and MCPs }\end{array}$ & $\begin{array}{l}\text { Garments must provide an effective barrier to control the } \\
\text { airborne dispersion of particles and MCPs from personnel } \\
\text { into the cleanroom }\end{array}$ & $\begin{array}{l}\text { The garment must be made of an occlusive fabric that is tightly } \\
\text { woven, with appropriate design considerations for areas such as } \\
\text { seams and fastenings, to ensure similar occlusive properties. }\end{array}$ \\
\hline 2. Non shedding & $\begin{array}{l}\text { Garments must not contribute to the level of } \\
\text { contamination by releasing particles into the cleanroom }\end{array}$ & $\begin{array}{l}\text { The garment fabric, sewing thread, and other garment constituents, } \\
\text { must be of a material that minimises the shedding of fibres or } \\
\text { particles. The garment decontamination process must minimise } \\
\text { surface particles and chemical residues that can be released into the } \\
\text { cleanroom. }\end{array}$ \\
\hline $\begin{array}{l}\text { 3. Electrically } \\
\text { conducting }\end{array}$ & $\begin{array}{l}\text { Garments are typically required to conduct away } \\
\text { electrostatic charges to avoid damage to equipment } \\
\text { sensitive to electrostatic discharge. Garments should not } \\
\text { build up an electrostatic charge that discharges and gives a } \\
\text { shock to the wearer when they touch an electrically } \\
\text { conductive surface. }\end{array}$ & $\begin{array}{l}\text { The garment fabric should incorporate an electro-conductive yarn as } \\
\text { a grid or stripe into the weave to provide electro-static discharge } \\
\text { (ESD) capability. }\end{array}$ \\
\hline $\begin{array}{l}\text { 4. Wearer coverage } \\
\text { and escape of } \\
\text { contaminated air }\end{array}$ & $\begin{array}{l}\text { Full-body coverage of the wearer is required to minimise } \\
\text { the airborne dispersion of particles and MCPs. }\end{array}$ & $\begin{array}{l}\text { The design of the garment needs to ensure all body area is covered, } \\
\text { with consideration of areas that interface with complementary } \\
\text { items such as gloves, face mask and eye coverings. The cuffs, necks, } \\
\text { ankles, and body opening should have effective closures to minimise } \\
\text { the escape of contaminated air from personnel. }\end{array}$ \\
\hline 5. Wearer comfort & $\begin{array}{l}\text { Wearer to be comfortable, without excessive perspiration. } \\
\text { There should be no significant restrictions of movement. } \\
\text { Garments to be unisex sizing. }\end{array}$ & $\begin{array}{l}\text { The garment fabric should have a level of air permeability that } \\
\text { allows sufficient exchange of air and water vapour. The garment } \\
\text { should correctly fit to permit appropriate movements. }\end{array}$ \\
\hline
\end{tabular}




\begin{tabular}{|l|l|l|}
\hline Consideration & Requirements & \multicolumn{2}{|c|}{ Comments } \\
\hline 6. Ease of donning & $\begin{array}{l}\text { Garment to be readily donned in a timely manner with } \\
\text { minimal microbial contamination transferred to the } \\
\text { outside surfaces of the garment from the person donning } \\
\text { the garment and from surfaces such as floors. }\end{array}$ & $\begin{array}{l}\text { The garment needs to be appropriately folded in the primary } \\
\text { packaging to facilitate the correct gowning procedure. }\end{array}$ \\
\hline $\begin{array}{l}\text { 7. Visible } \\
\text { appearance }\end{array}$ & $\begin{array}{l}\text { Garments to be of an appropriate visual appearance that } \\
\text { shows the importance of the cleanroom. }\end{array}$ & $\begin{array}{l}\text { Garments should be withdrawn from use after a defined lifetime } \\
\text { that is typically related to the number of decontamination cycles. } \\
\text { Any repairs of reusable garments need to be controlled by utilising } \\
\text { the same garment material and colour and repaired to an agreed } \\
\text { standard. }\end{array}$ \\
\hline 8. Cost & Garment to be cost effective. & $\begin{array}{l}\text { The cost of reusable garments needs to be considered with respect } \\
\text { to the capital cost of the garment, and garment decontamination } \\
\text { costs which are related to the number of decontamination cycles } \\
\text { that are acceptable over the lifetime of the garment. }\end{array}$ \\
\hline
\end{tabular}

\section{Considerations of choice of fabric for re-usable garments}

For re-usable garments, the requirements for garment fabrics that are summarised in Table 1 are discussed in this section. The design and effectiveness of garments are discussed in Section 4.

\subsection{Garment Fabric}

A key consideration for effective contamination control is the garment fabric. Popular everyday fabrics are made from either cotton or a mixture of polyester and cotton (polycotton). Polycotton fabrics are woven from yarns made by twisting together the short staple fibres of cotton with the continuous fibres of polyester to form a cohesive yarn. Shown in Figure 1 is the magnified (x 50) image of a polycotton fabric. It can be seen why this fabric, as well as cotton fabrics are not suitable for cleanroom applications as the fibre ends protrude from these yarns and are constantly broken off during normal wear and both fibres and small particles are continually shed into the cleanroom.

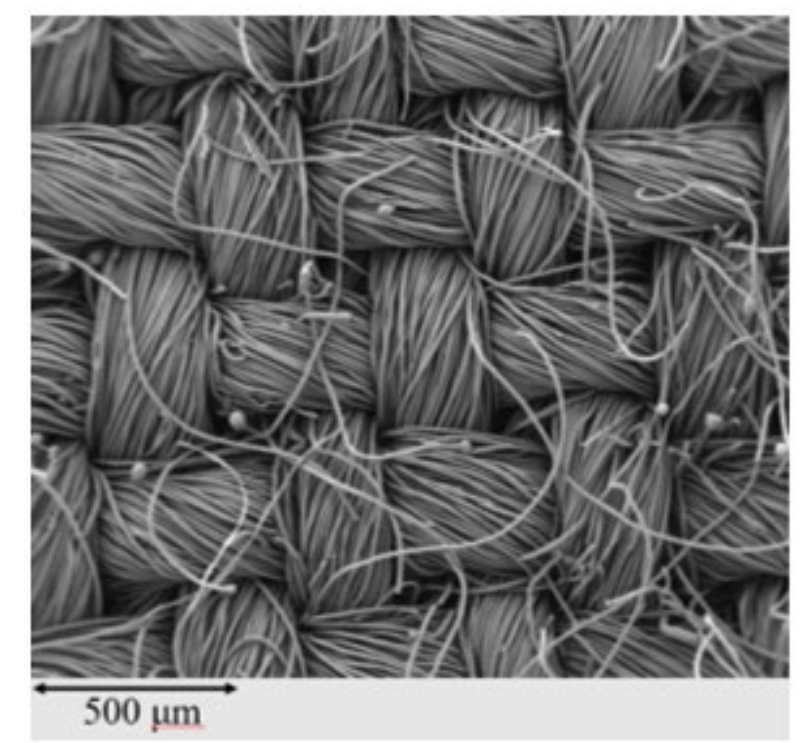

Figure 1 Polycotton fabric showing protruding fibre Ends (x 50 magnification).

The solution to the problem of the particle and fibre shedding by cotton and polycotton fabrics is to use monofilament plastic thread to produce the yarn. The continuous nature of this yarn ensures that fibre and particle shedding is greatly reduced. The most commonly re-usable woven fabrics used in cleanrooms are currently made from $100 \%$ monofilament polyester. Shown in Figure 2 is the integral and continuous nature of this type of fabric.

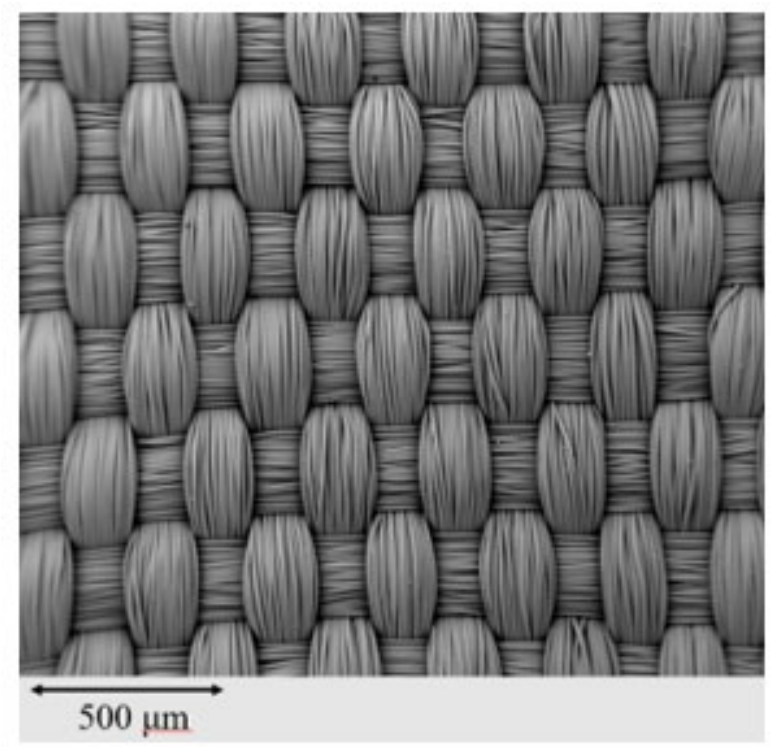

Figure 2 100\% monofilament polyester fabric (x 50 magnification).

Pores occur in fabrics where the yarns cross and these pores determine the rate at which particles, air, and water vapour, pass through. To minimise the transfer of airborne contaminants from wearer to cleanroom, the fabric must be tightly and reliably woven to produce a small pore size of a consistent size. The tightness of the weave of cotton or polycotton fabric is normally inadequate to control the dispersion of skin and clothing particles from the wearer, 
including those that carry microbes, as they will easily pass through the space where the yarns cross. However, it is not only cotton and polycotton fabrics that suffer from this problem as fabrics made from monofilament fibres can also be ineffective. Shown in Figure 3 is a fabric woven from monofilament thread which has large pores with an equivalent pore diameter of about $100 \mu \mathrm{m}$. This fabric is ineffective in reducing the dispersion of particles and MCPs from personnel as they can easily pass through it. Garments used in cleanrooms should, therefore, be manufactured from a fabric that is tightly woven from monofilament thread.

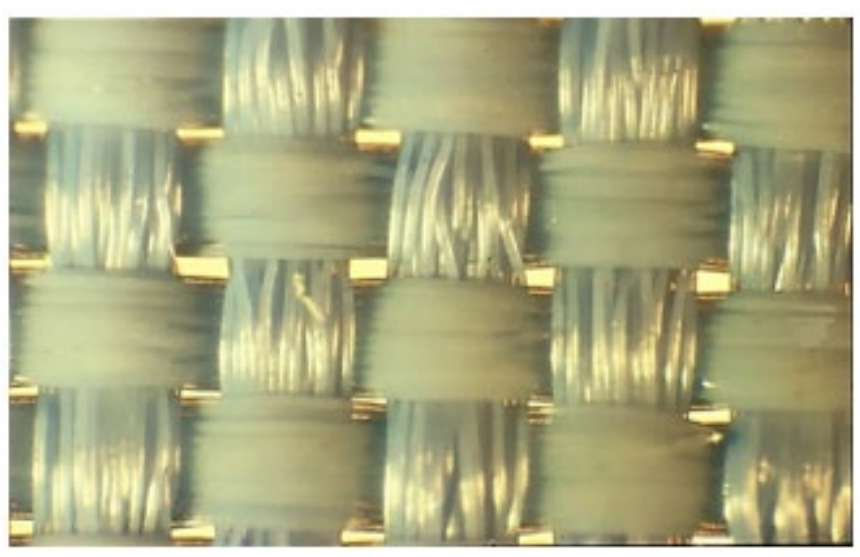

Figure 3 Monofilament fabric showing large pores with an equivalent particle diameter of approximately $100 \mu \mathrm{m}$.

Woven monofilament fabrics used in cleanrooms benefit from a conductive carbon stripe or grid incorporated into the fabric. The conductive carbon fibres are not readily visible in Figure 2 as the image contrast obtained by a SEM is based on the differences between the atomic masses of the materials. Both the conductive grid and the fabric fibres have a chemical structure that is mainly carbon based and there is, therefore, very little contrast between them.

\subsection{Fabric Test Methods}

To assess the likely performance of a reusable fabric in a cleanroom, it is necessary to test a range of its properties. It is common to find that the fabric's properties are provided by the manufacturer but several of these properties may not be directly relevant to the contamination control needs of a pharmaceutical or healthcare cleanrooms. No ISO standard exists that details the relevant properties required for a cleanroom fabric but IEST-RP-003.4 6 includes contamination control property tests developed by Whyte and Bailey 1,2 for use in cleanrooms. Test methods also exist as national standards that cover individual properties of fabrics and these are often combined, although different fabric manufacturers use different tests to describe their fabrics. It is therefore, important to ensure the fabrics have been subject to relevant test methods and the tests that the authors consider the most important are given in Table 2.

Table 2 Fabric test methods

\begin{tabular}{|c|c|}
\hline Test & Test Description \\
\hline Equivalent pore diameter & $\begin{array}{l}\text { A bubble point test is used to determine the equivalent diameter of the fabric's pores which pass from one side of the } \\
\text { fabric to the other and relate to the tightness and accuracy of the fabric weave. A smaller pore size gives a better particle } \\
\text { barrier performance against contamination shed by personnel but decreases the ability of the fabric to allow the passage } \\
\text { of air and water vapour and hence operator comfort. Care must be taken to ensure that the pore size in units of } \\
\text { micrometres }(\mu \mathrm{m}) \text { is expressed as the diameter and not the radius. }\end{array}$ \\
\hline Particle removal efficiency & $\begin{array}{l}\text { The fabric is subjected to an airstream challenge containing a known concentration of particles of different sizes and the } \\
\text { number of particles that pass through the fabric is measured and reported as filtration efficiency. }\end{array}$ \\
\hline Dry linting propensity & $\begin{array}{l}\text { The number of particles generated by the fabric. This can be carried out by a standard flexing test under mild abrasion, } \\
\text { or by the Helmke drum test. }\end{array}$ \\
\hline Water vapour permeability & $\begin{array}{l}\text { The rate of transfer of water vapour through an area of fabric is determined and provides an indication of garment } \\
\text { comfort. The faster the moisture is transferred from the wearer, the higher the level of comfort. }\end{array}$ \\
\hline Air permeability & $\begin{array}{l}\text { The rate of transfer of air through an area of fabric is determined. Personnel are often too hot in a cleanroom and if air } \\
\text { can pass easily through the fabric, the wearer will be more comfortable. However, this test also shows the likely } \\
\text { effectiveness in preventing airborne contamination from personnel passing through the fabric as the lower the air } \\
\text { permeability the more effective the fabric is likely to be. }\end{array}$ \\
\hline Static dissipation behaviour & Determines the electro-static dissipative (ESD) properties of the fabric. \\
\hline Abrasion resistance & nce to wear, characteristics of the $f$ \\
\hline
\end{tabular}

\section{Fabric investigated}

The manufacturer's specification of the monofilament polyester fabric that was investigated is shown in Table 3 and, where applicable, the test method is included in parenthesis. The fabric investigated was a JG type (WF5505-JG) supplied by Asiatic Fiber Corporation and is widely utilised for garments in the pharmaceutical industry. However, without a detailed knowledge of fabrics and the test methods used, it is difficult to understand from the information given in Table 3 how well the fabric would perform in a pharmaceutical or healthcare cleanroom to the required parameters shown previously in Table 2.

Table 3 Specification for mono filament polyester fabric JG (WF5505-JG)

\begin{tabular}{|l|l}
\hline Fabric Parameter & Specification \\
\hline Composition & $\begin{array}{l}98 \% \text { Polyester filament yarn }+2 \% \text { polyester carbon compound filament yarn } \\
\text { (ASTM-D-629) }\end{array}$ \\
\hline
\end{tabular}




\begin{tabular}{|c|c|}
\hline Fabric Parameter & Specification \\
\hline Weight & $144 \mathrm{~g} / \mathrm{y} 100 \mathrm{~g} / \mathrm{m}^{2} \mathrm{~g} \pm 5 \%$ \\
\hline Width & 60 inch $152 \mathrm{~cm} \pm 1 \%$ \\
\hline $\begin{array}{r}\text { Density warp } \\
\text { weft }\end{array}$ & $\begin{array}{l}176 \text { ends/inch } 69 \text { ends/cm } \\
94 \text { ends/inch } \quad 37 \text { ends/cm }\end{array}$ \\
\hline Weave & Plain weave with $5 \mathrm{~cm}$ square conductive yarn \\
\hline $\begin{array}{r}\text { Yarn type warp } \\
\text { weft }\end{array}$ & $\begin{array}{l}\text { Polyester 72D/72f +Conductive Yarn } \\
\text { Polyester 75D/72f +Conductive Yarn }\end{array}$ \\
\hline Surface Resistivity & $10^{8-9} \mathrm{ohm} /$ square at $42 \% \mathrm{RH}, 21^{\circ} \mathrm{C}$ (DIN-54345) \\
\hline $\begin{array}{l}\text { Friction Charges, } \\
\text { Electrification Potential }\end{array}$ & $\begin{array}{l}\text { Warp } 28 \mathrm{~V} \\
\text { Weft } 15 \mathrm{~V} \\
\text { (JISL1094-B before wash) }\end{array}$ \\
\hline Decay Time & $\begin{array}{l}\text { Warp } \pm 0.01 \mathrm{sec} \\
\text { Weft } \pm 0.01 \mathrm{sec} \\
\text { (NFPA-99) }\end{array}$ \\
\hline Air Permeability & $\begin{array}{l}4.01 \mathrm{cfm} \\
\text { (ASTM D737) }\end{array}$ \\
\hline Tensile Strength & $\begin{array}{l}\text { Warp 63.0kg } \\
\text { Weft } 69.4 \mathrm{~kg} \\
\text { (ASTM D5034) }\end{array}$ \\
\hline Tear Strength & $\begin{array}{l}\text { Warp 2640g } \\
\text { Weft 2440g } \\
\text { (ASTM D1424) }\end{array}$ \\
\hline Application & For Class 1 -10 cleanroom garment and shoes \\
\hline
\end{tabular}

\section{Assessment of Fabric Performance}

The fabric specification shown in Table 3 relates to new garments that have not been subjected to any decontamination cycles. For re-usable garments, it is important to determine the condition of the fabric after a number of decontamination cycles, in order to define an appropriate garment lifetime. To assess the condition of the fabric following decontamination, garments fabricated from JG (WF5505-JG) material were subjected to a number of accelerated standard decontamination cycles (wash, dry, primary pack and gamma radiation sterilisation at $25 \mathrm{kGy}$ ) completed by a specialised cleanroom garment laundry company. Fabric from garments that had completed 10, 25, 50 and 70 cycles were tested and compared with new (no decontamination cycles) garment fabric by an independent specialist testing company, using the following test methods, to evaluate key contamination control parameters.

1. Visual appearance

2. Equivalent pore diameter (IEST-RP-CC003.4. $2011^{6}$ )

3. Particle removal efficiency (In-house test based on IEST-RP-CC003.4. 2011 method ${ }^{6}$ )

4. Dry linting propensity (ISO 9073-10 ${ }^{8}$ )

5. Scanning electron microscopy (SEM) imaging to determine any change to the fabric structure. 


\section{Results}

The results of the testing are shown in Figure 4 to Figure 8 for visual appearance, equivalent pore diameter, particle removal efficiency, dry linting propensity, and SEM imaging parameters, respectively.

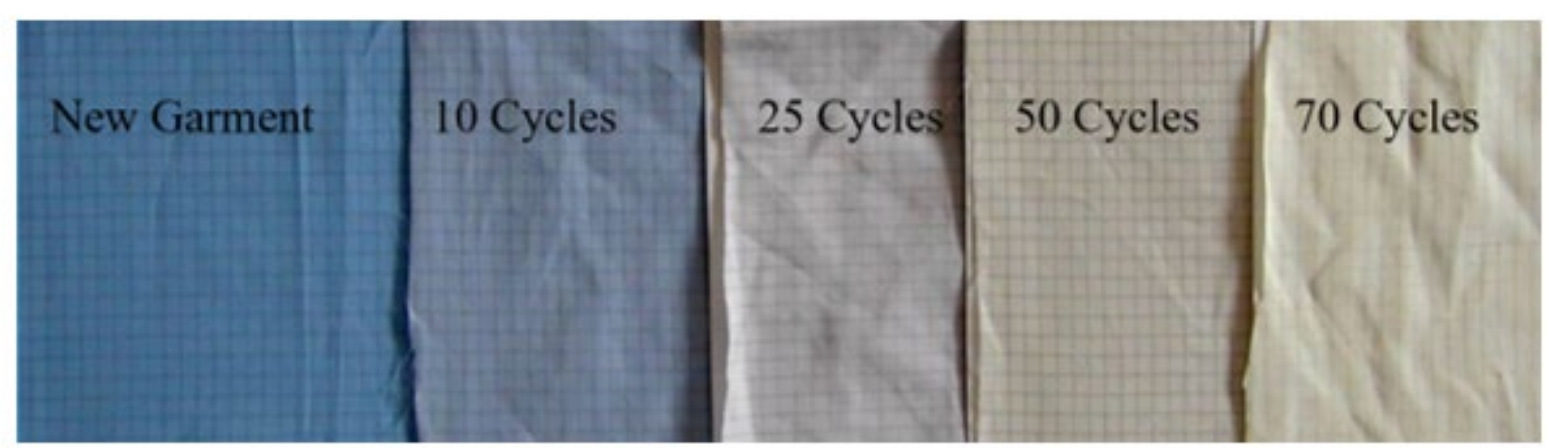

Figure 4 Visual appearance of garment fabric after defined number of decontamination cycles

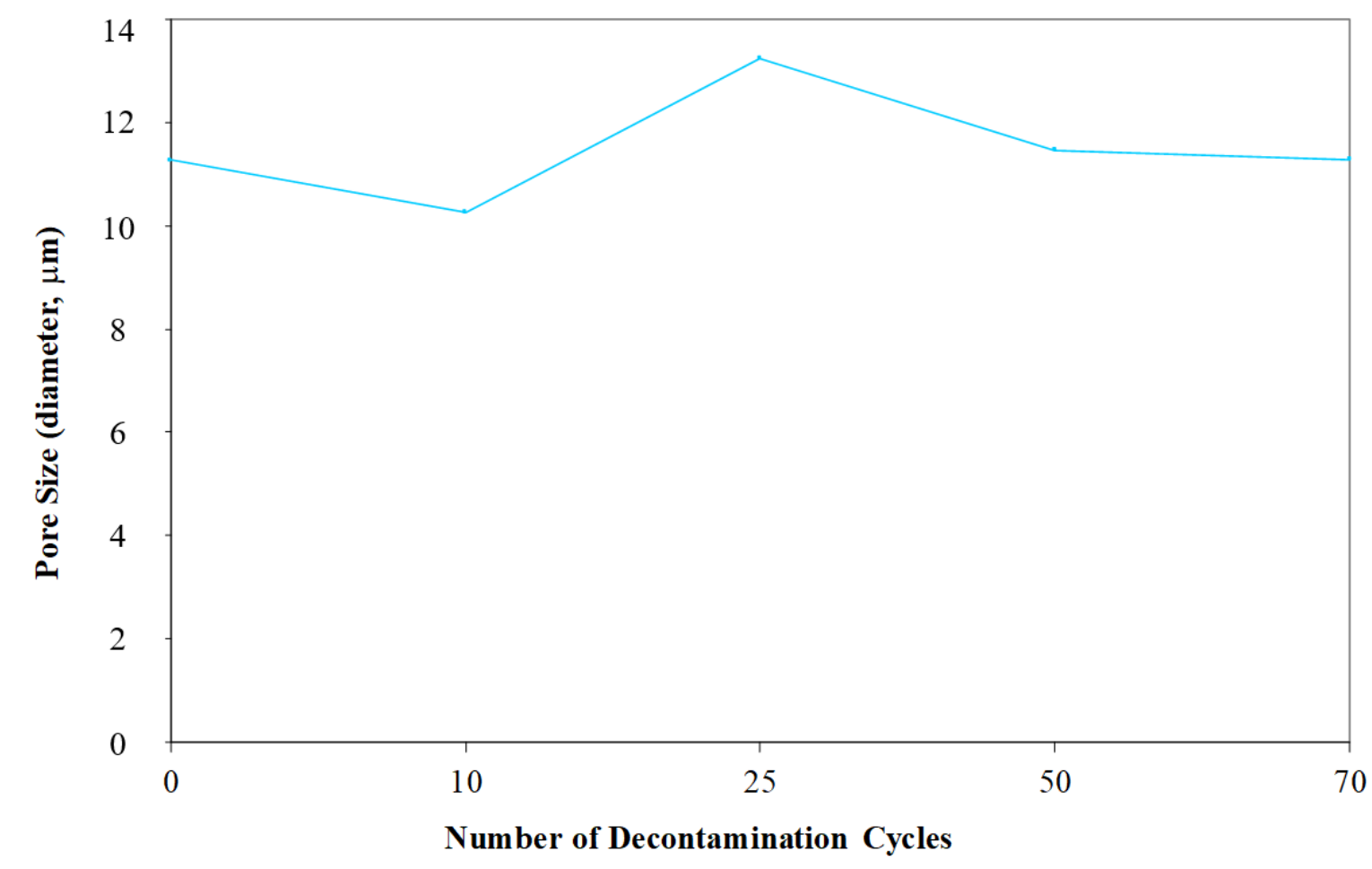

Figure 5 Fabric equivalent pore diameter after defined number of cycles

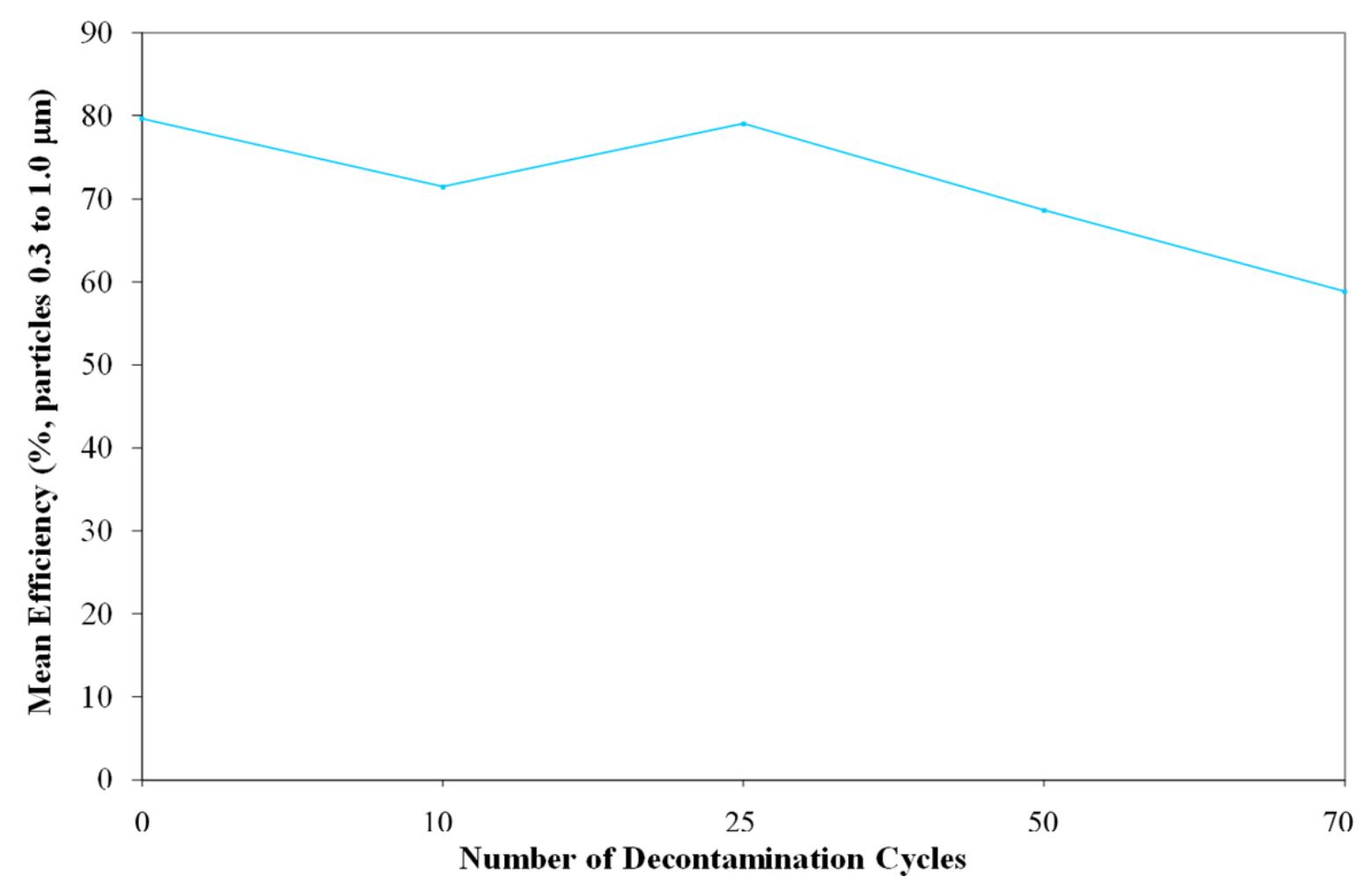

Figure 6 Average particle removal efficiency of particles $\geq 0.3$ ? $\mathrm{m}, \geq 0.4$ ? $\mathrm{m}, \geq 0.5$ ? $\mathrm{m}, \geq 1$ ? $\mathrm{m}$ after defined number of decontamination cycles. 

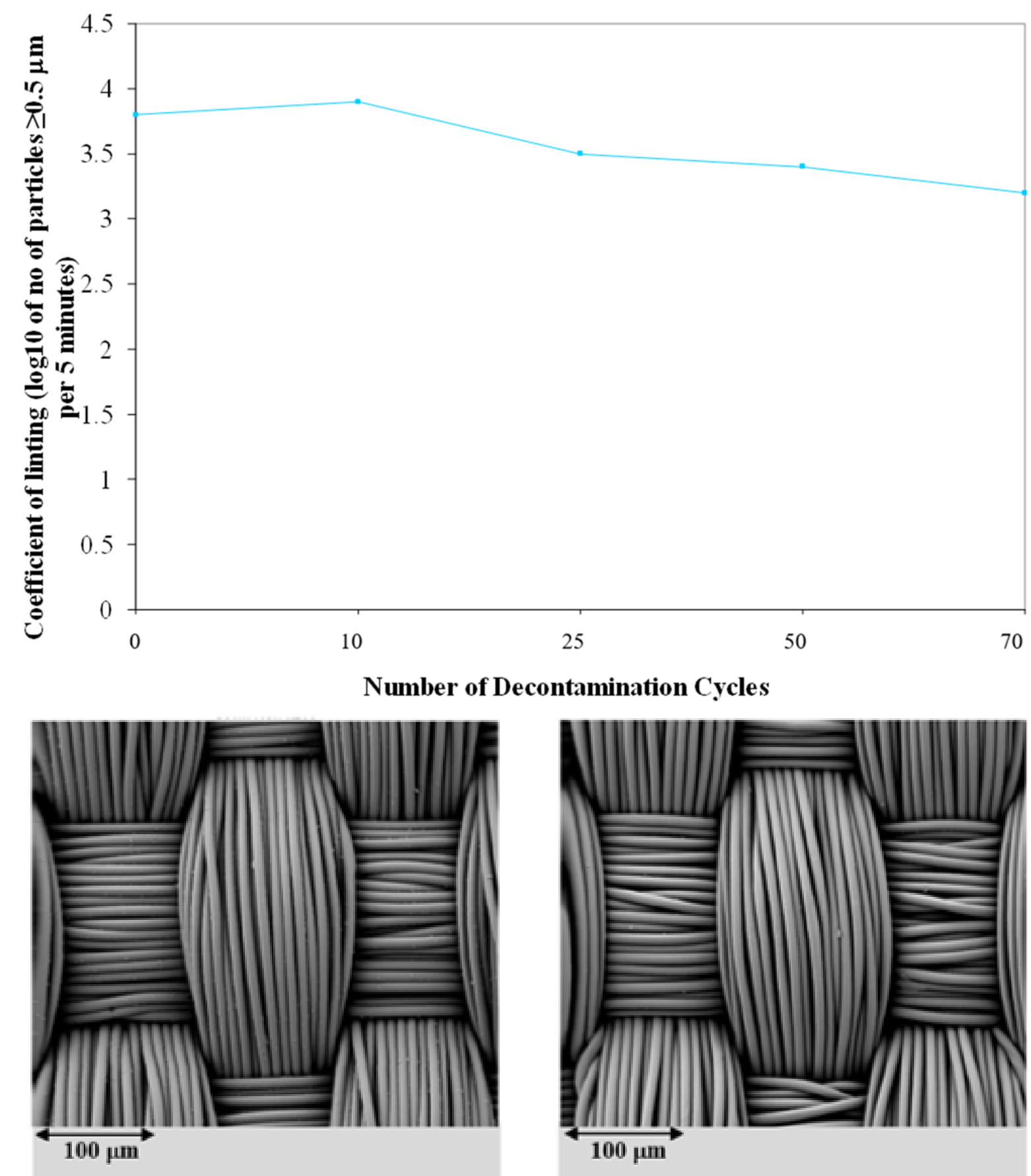

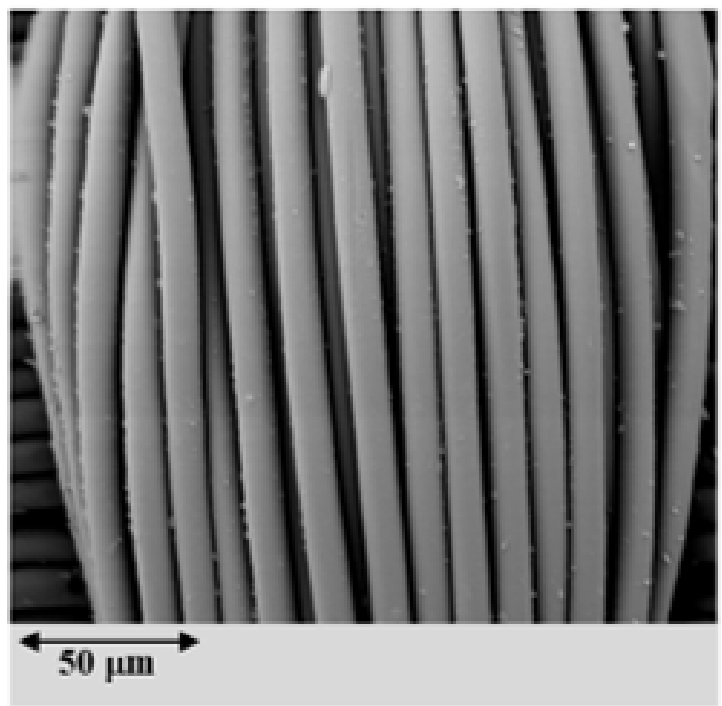

New fabric

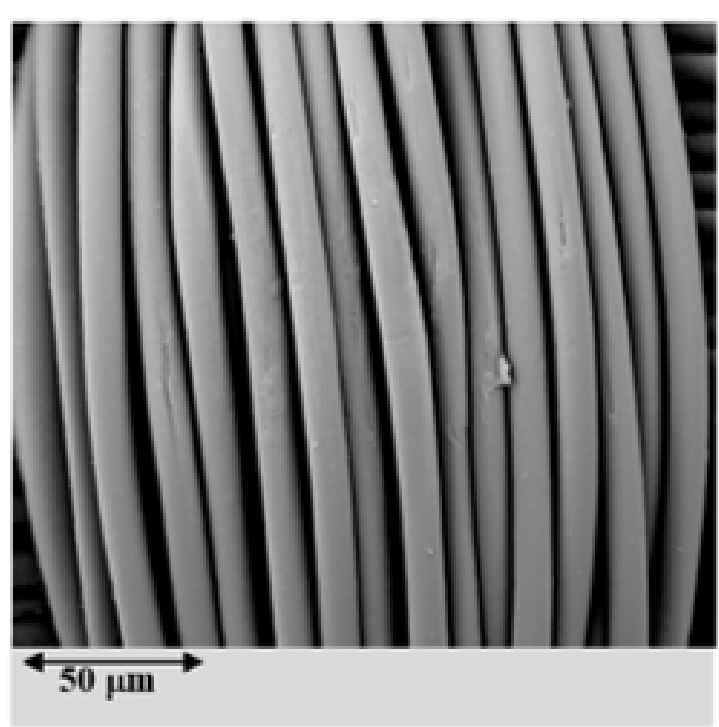

Fabric 50 decontamination cycles

Figure 8 New fabric (left) and fabric that has been subjected to 50 decontamination cycles (right) Magnification of upper photographs $\times 200$ and lower photographs $\times 500$

\section{Determination of Overall Garment Effectiveness}

\subsection{Design of Garment Studied}

The garment studied in the dispersal chamber to find the dispersion rate of MCPs from personnel was as follows. The garment was produced from the fabric being studied and designed to ensured that all skin surfaces of the wearer were covered. It consisted of boots, gloves, hood, and mask and is typical of garments used in an EU GGMP 9 Grade B cleanroom. It is shown in Figure 9 . The fabric edges were sealed before being sown together to ensure no fibre break-out within the enclosed seams. The number of seams were minimised and totally enclosed using a double stitching technique to encapsulate all cut and sealed edges. To enhance operator comfort and ease of donning, stud fastenings for personal adjustments around the wrist, neck, and hood area's were avoided and elasticated wrists and quick adjust ladder lock fastenings utilised. The coverall fastening was achieved with a tight fitting (spiral design) polyester zipper which was further protected with a material flap (placket) to provide additional containment. 


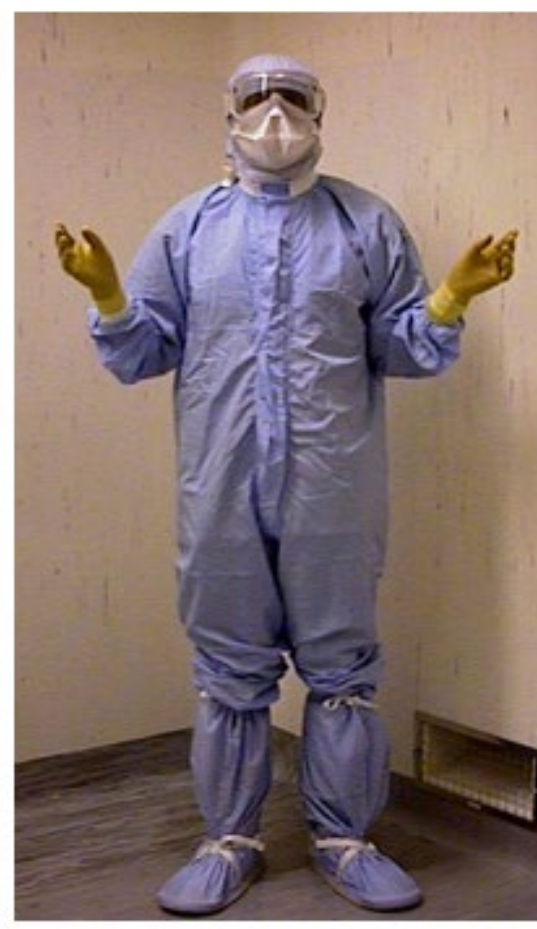

Figure 9 Cleanroom garment and associated attire studied

\subsection{Test method}

The total contamination control effectiveness of the design of a garment and its fabric can be determined by use of a dispersal chamber. A dispersal chamber was first described by Whyte, who used a chamber supplied with a known quantity of filtered air to ascertain the dispersion rate of MCPs from people wearing different clothing ${ }^{10}$

The dispersal chamber used in these experiments is shown in Figure 10. It is $0.7 \mathrm{~m} \times 0.5 \mathrm{~m} \times 2 \mathrm{~m}$ high and made of a metal frame with glass sides and a variable speed fan which supplies particle free air from a HEPA filter at the top of the chamber. The volume of particle free air that is supplied to the chamber is just over $700 \mathrm{~L} / \mathrm{min}$, and is balanced by the removal of air by a high-volume bacterial sampler (Casella slit sampler) operating at $700 \mathrm{~L} / \mathrm{min}$ and connected to the base of the chamber via a sampling duct. The Casella sampler had recently been calibrated and had an air velocity through its slits of 66 $\mathrm{m} / \mathrm{s}$ and $d_{50}$ of $0.8 \mu \mathrm{m}$. A calibrated particle counter (Lasair-310) operating at $28.3 \mathrm{~L} / \mathrm{min}$ was connected to a separate sampling port that is also located at the base of the chamber. The rate at which airborne particles and MCPs are dispersed from personnel is therefore measured. The detailed operation of such a chamber is discussed elsewhere ${ }^{11}$.

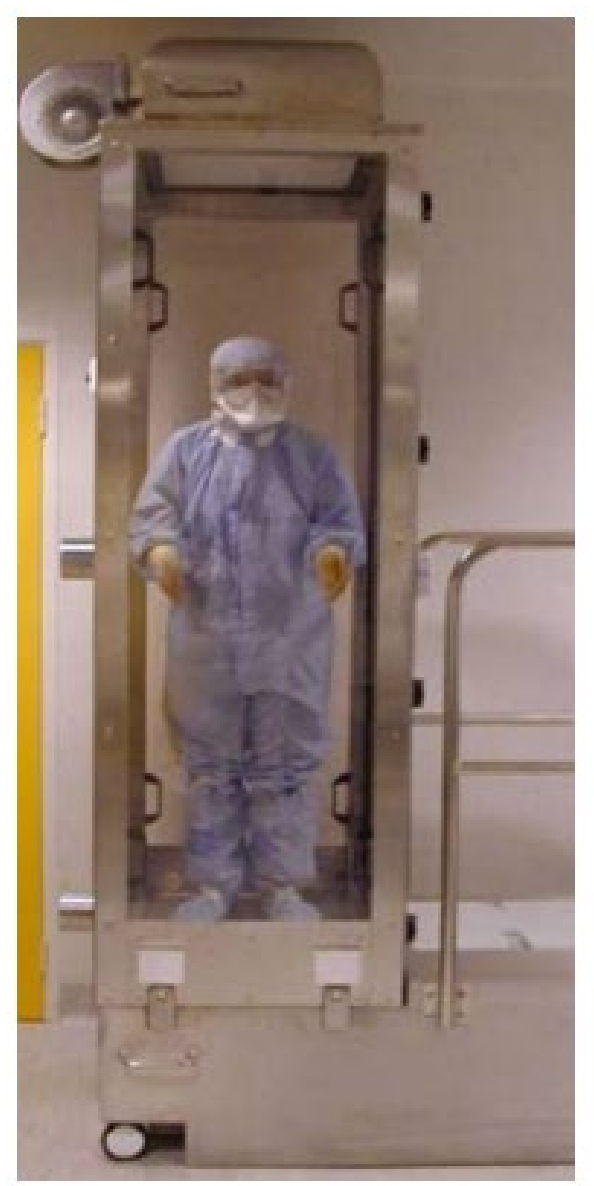

Figure 10 Dispersal chamber used for testing garments

Testing was carried out on 3 people ( 2 males, 1 female). Each subject was tested as they marched on the spot and moved their arms up to their shoulders at a rate of 1 per second. This was carried out while wearing both cleanroom undergarments, and cleanroom garments on top of the undergarments. The subjects exercised for 1 minute until the airborne contamination reached a steady state and continued to exercise during air sampling. The air sampling was carried out for 1 or 5 minutes, depending upon expected dispersion rates. There was a 5 -minute interval between each test to ensure an adequate clean up period.

The undergarments consisted of a short-sleeved top with separate trousers made from a polyester and cotton mix and are specialist pharmaceutical undergarments suitable for wearing beneath cleanroom garments and complemented by mop cap and plant shoes. The cleanroom garments and complementary items were those discussed in the previous sections of this article, and all had completed 50 decontamination cycles.

The air sampler utilised plates containing tryptone soya agar, supplemented with $0.5 \%$ polysorbate 80 . Polysorbate 80 is commonly used to neutralise disinfectants in cleanrooms but this was not the purpose in this situation. It was used to provide fatty acids (oleic acid) as a source of nutrition to aid the growth of lypophilic skin bacteria. All plates were incubated before use and checked for sterility. After use, the plates were incubated aerobically at $32.5^{\circ} \mathrm{C}\left( \pm 1.5^{\circ} \mathrm{C}\right)$ for 3 days and examined for microbial growth. Due to the determined combined losses from the Casella air sampler and the air intake duct, the resultant counts were multiplied by a factor of 2.6 to take this into account ${ }^{11}$. The particle counter simultaneously recorded the concentrations of the total particles $\geq 0.5 \mu \mathrm{m}$ 
and $\geq 5.0 \mu \mathrm{m}$ per $\mathrm{m}^{3}$ during the exercising. With knowledge of the air supply rate to the dispersal chamber and the sampling rate of the air samplers the dispersion rate was obtained.

\subsection{Results from dispersal chamber}

Shown in Tables 4 and 5, respectively, are the dispersion rates of particles $\geq 0.5 \mu \mathrm{m}$ and $\geq 5 \mu \mathrm{m}$ and MCPs for the subjects when wearing undergarments and when wearing cleanroom garments on top of undergarments. These tables also include the average dispersion rates and the number of times reductions when comparing cleanroom garments to undergarments. Dispersal rates are normally reported as number per second, but as it is easier to comprehend dispersal rates per minute, these are the units utilised in Tables 4 and 5 . All the results are rounded to whole numbers and are shown graphically in Figure 11.

Table 4 Dispersion rates per minute, particles $\geq 0.5 \mu \mathrm{m}$ and $\geq 5 \mu \mathrm{m}$, when wearing undergarments and cleanroom garments

\begin{tabular}{|c|c|c|c|c|}
\hline Person & Particle size & Undergarments & $\begin{array}{l}\text { Cleanroom } \\
\text { garments }\end{array}$ & $\begin{array}{c}\text { Times Reduction } \\
\text { (cleanroom garments vs. } \\
\text { undergarments) }\end{array}$ \\
\hline Male 1 & \multirow{4}{*}{$\geq 0.5 \mu \mathrm{m}$} & 1783068 & 37791 & 47 \\
\hline Male 2 & & 1549431 & 46436 & 33 \\
\hline Female & & 492271 & 25688 & 19 \\
\hline Average & & 1274923 & 36638 & 35 \\
\hline Male 1 & \multirow{4}{*}{$\geq 5 \mu \mathrm{m}$} & 453986 & 1803 & 250 \\
\hline Male 2 & & 343824 & 2655 & 130 \\
\hline Female & & 100282 & 1469 & 70 \\
\hline Average & & 299364 & 1975 & 151 \\
\hline
\end{tabular}

Table 5 Dispersion rates per minute, MCPs, when wearing undergarments and cleanroom garments

\begin{tabular}{|l|c|c|c|}
\multicolumn{1}{|c|}{ Person } & Undergarments & $\begin{array}{c}\text { Cleanroom } \\
\text { garments }\end{array}$ & $\begin{array}{c}\text { Times Reduction } \\
\text { (cleanroom garments vs. } \\
\text { undergarments) }\end{array}$ \\
\hline Male 1 & 2438 & 13 & 188 \\
\hline Male 2 & 2205 & 11 & 201 \\
\hline Female & 1178 & 6 & 196 \\
\hline Average & $\mathbf{1 9 4 0}$ & $\mathbf{1 0}$ & $\mathbf{1 9 4}$ \\
\hline
\end{tabular}

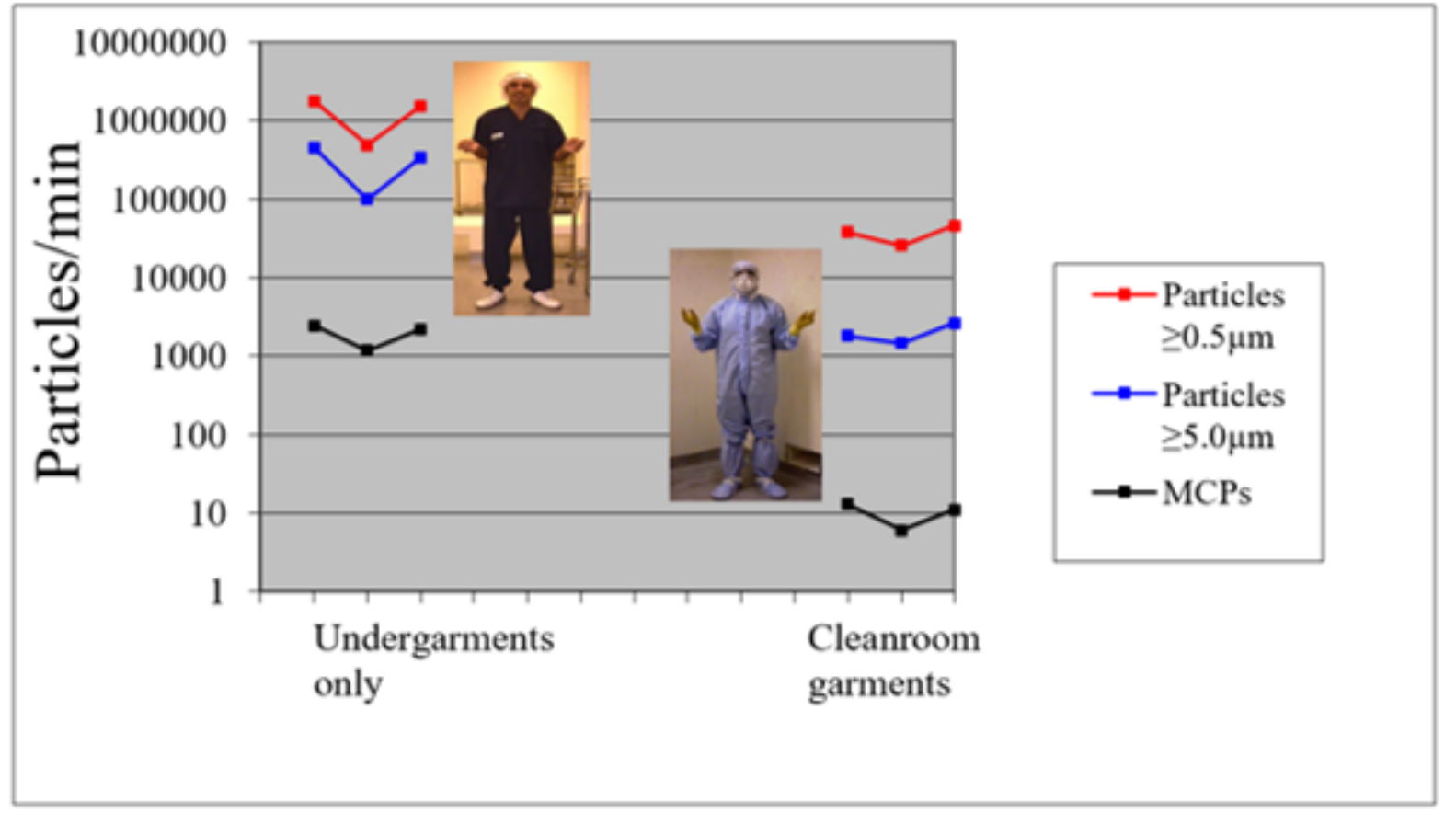

Figure 11 Dispersion rates of MCPs and particles from 3 people wearing cleanroom undergarments and cleanroom garments

\section{Discussion and conclusions}

Information is provided in this article about tests used to determine the contamination control properties of fabrics used to manufacture garments worn in pharmaceutical and healthcare cleanrooms. These tests can be used when garments are first selected for use in the cleanroom but in this article, they were used to investigate the deterioration of new garments. Tests were carried out on a previously unstudied fabric when new, and after $10,20,50$ and 70 decontamination cycles. These cycles included washing, drying, sterilisation by gamma radiation. It is probable that sterilisation by autoclaving would have given different results, but this was not investigated.

The appearance of the fabric was observed as the number of decontamination cycles increased from new to 70 cycles and there was a clear loss in the fabric colour, as shown in Figure 4. In addition, the fabric was noticeably thinner after 70 cycles and it was difficult to put on garments without tearing the fabric. This change in the fabric was thought to indicate deterioration in the contamination control properties of the fabric and was investigated.

The weave of the fabric was observed by a scanning electron microscope and images are shown in Figure 8 of the new fabric and after 50 decontamination cycles. After 50 cycles, the fabric was shown to maintain a tight and consistent weave, with no indication of material breakdown, including the integral carbon encapsulated grid, and there was little or no difference from the new fabric. However, although no image is included in this article, it was found that after 70 cycles, there was a break-up of the carbon encapsulated grid.

As reported in the table in Figure 5, the equivalent pore diameter of the new fabric was $11.3 \mu \mathrm{m}$ and a reasonably consistent profile of pore size was maintained throughout the increasing number of decontamination cycles. After 70 cycles the pore size was the same as the new fabric. Pore size is a key 
parameter used to predict the ability of a woven fabric to provide effective barrier and containment control, and the smaller the pore size the more effective the control. It was expected that the particle removal efficiency would maintain a similar consistent profile through decontamination cycles. However, this was only partly confirmed by the results given in the table in Figure 6 , as the overall drop in particle removal efficiency after 50 cycles was found to be $13.9 \%$, and after 70 cycles it was $26.1 \%$.

Tests were also carried out on the release of particles from the fabric (dry linting propensity). The results are given in the table in Figure 7 and they showed an increase in particles after 10 contamination cycles but all subsequent results up to 70 cycles were less than those recorded for the new fabric

When taking into account all of the above information, it is considered that a limit of 50 decontamination cycles should be placed on the use of the fabric studied before replacement. To confirm this, and to study the dispersion rates of MCPs from garments worn by personnel and made from this fabric, a dispersal chamber was used. Only one set of results was obtained from the three personnel who participated but the dispersal profiles from each individual were consistent. The control of dispersion of particles is related to the pore size of the garment's fabric and, therefore, the larger the particle, the more effective the fabric will be. This was confirmed by the reductions of particles $\geq 0.5 \mu \mathrm{m}, \geq 5.0 \mu \mathrm{m}$, and MCPs (average size typically $12 \mu \mathrm{m} 11,12$ ), which gave average reductions compared to cleanroom undergarments of 35, 151 and 195-fold, respectively. It was also found that the average dispersion rate of MCPs from the three personnel when wearing garments that had gone through 50 decontamination cycles was $10 /$ minute $(0.2 / \mathrm{s})$. This was close to the lower dispersion rate from personnel wearing garments made from different fabrics that had gone through 50 decontamination cycles and reported by Ljungqvist and Reinmuller 4 to have satisfactory emission rates of $9.8 / \mathrm{s}, 1.9 / \mathrm{s}, 0.1 / \mathrm{s}$ and $0.2 / \mathrm{s}$.

Using the information from the contamination control tests of the fabric studied and the dispersion rate in the chamber, it appears that the control of the dispersion of MCPs by the fabric and garments was satisfactory up to 50 decontamination cycles but not 70 . However, it has been shown that different fabrics will give different rates of change of their contamination control performances over time 2 , and it is also likely that the type of decontamination cycle will affect the rate of deterioration of fabrics. It may, therefore, be considered appropriate to investigate garments when first introduced into a cleanroom, and over time, by the use of tests described in this article to determine how many decontamination cycles can be used before garments lose their contamination control effectiveness. 


\section{References}

Whyte W and Bailey PV. Reduction of microbial dispersion by clothing. Journal of Parenteral Science and Technology 1985; 39(1): 51-60. Whyte W and Bailey PV. Particle dispersion in relation to clothing. The Journal of Environmental Sciences 1989, March/April: 43-49.

Ljungqvist B and Reinmuller B. People as a contamination source: cleanroom clothing systems after 1, 25 and 50 washing /sterility cycles. European Journal of Parenteral and Pharmaceutical Sciences 2003; 8(3): 75-80.

Romano F, Ljungqvist B, Reinmuller B, Gusten J and Joppolo CM. Performance test of technical cleanroom clothing systems Proceedings of Indoor Air 2016, $14^{\text {th }}$ International Conference on Indoor Air Quality and Climate, Ghent, Belgium, 2016.

Ljungqvist B and Reinmüller B. People as a contamination source-dispersal chamber evaluation of clothing systems for cleanroom and ultra clean operation rooms. Report number D2014:01, Chalmers University of Technology, Sweden, 2014.

IEST-RP-CC003.4. Garment system considerations for cleanrooms and other controlled environments. Institute of Environmental Sciences and Technology. 2011

Clayton N and Eaton T. The Micronclean big blue cleanroom handbook. 2011. ISBN 9780-9570735-0-0.

ISO 9073-10:2003. Textiles. Test methods for nonwovens. Lint and other particles generation in the dry state. International Organization for Standardization, Geneva, Switzerland.

EU GGMP (2008). The rules governing medicinal products in the European Union -Volume 4 -EU guidelines to good manufacturing practice - medicinal products for human and veterinary use - Annex 1-Manufacture of sterile medicinal products. European Commission, Brussels.

Whyte W, Vesley D and Hodgson R. Bacterial dispersion in relation to operating clothing. Journal of Hygiene 1976; 76: $367-378$.

Whyte W and Hejab M. Particle and microbial airborne dispersion from people. European Journal of Parenteral and Pharmaceutical Sciences 2007; 12 (2):

39-46.

Noble WC, Lidwell OM and Kingston D. The size distribution of airborne particles carrying micro-organisms. Journal of Hygiene 1963; 61:385-391. 


\section{Appendix A: ISO 14644-1 and EU GGMP Annex 1 room occupancy definitions}

Table A1 Cleanroom occupancy definitions given by ISO 14644-1:2015 and EU GGMP Annex 1 (2008)

\begin{tabular}{|l|l|l|l|}
\multicolumn{1}{c|}{$\begin{array}{l}\text { Document } \\
\text { reference }\end{array}$} & \multicolumn{1}{c|}{ As-Built } & \multicolumn{1}{c|}{ At-Rest } & \multicolumn{1}{c|}{ Operational a } \\
\cline { 2 - 4 } $\begin{array}{l}\text { EU GGMP } \\
\text { Annex 1: } 2008\end{array}$ & No definition included. & $\begin{array}{l}\text { The condition where the } \\
\text { installation is installed } \\
\text { and operating, complete } \\
\text { with production } \\
\text { equipment but with no } \\
\text { operating personnel } \\
\text { present. }\end{array}$ & $\begin{array}{l}\text { The condition where the } \\
\text { installation is functioning } \\
\text { in the defined operating } \\
\text { mode with the specified } \\
\text { number of personnel } \\
\text { working. }\end{array}$ \\
\hline ISO14644-1: 2015 & $\begin{array}{l}\text { The condition where the } \\
\text { cleanroom or clean zone } \\
\text { is complete with all } \\
\text { services connected and } \\
\text { functioning but with no } \\
\text { equipment, furniture, } \\
\text { materials or personnel } \\
\text { present. }\end{array}$ & $\begin{array}{l}\text { The condition where the } \\
\text { cleanroom or clean zone } \\
\text { is complete with } \\
\text { equipment installed and } \\
\text { operating in a manner } \\
\text { agreed upon, but with no } \\
\text { personnel present. }\end{array}$ & $\begin{array}{l}\text { The agreed condition } \\
\text { where the cleanroom or } \\
\text { clean zone is functioning } \\
\text { in the specified manner, } \\
\text { with equipment } \\
\text { operating and with the } \\
\text { specified number of } \\
\text { personnel present. }\end{array}$ \\
\hline
\end{tabular}

Note:

a. Annex 1 of the EU GGMP refers to 'in operation' and the ISO 14644-1 standard refers to 'operational' but these two terms are considered to be equivalent.

\section{Appendix B: ISO 14644-1:2015 and EU GGMP Annex 1 (2008) airborne cleanliness concentrations}

Shown in Table B1 are the airborne cleanliness concentrations for particles $\geq 0.5 \mu \mathrm{m}$ and $\geq 5 \mu \mathrm{m}$ given in ISO $14644-1$ and the EU GGMP Annex 1 (2008). It should be noted that ISO standard 14644-1 allows airborne classification in three occupancy states and the associated occupancy state must be stated. Annex 1 of the EU GGMP only consider two occupational states. Shown in the table are the ISO 14644-1 concentrations considered to correspond with the EU GGMP Annex 1 concentrations for the 'at rest' and 'in operation' occupancy states.

Table B1 Comparative airborne cleanliness concentrations of $\geq 0.5 \mu \mathrm{m}$ and $\geq 5 \mu \mathrm{m}$ particle sizes given in ISO 14644-1: 2015 and EU GGMP Annex 1 (2008).

\begin{tabular}{|c|c|c|c|c|c|}
\hline \multirow[t]{3}{*}{ Document reference } & \multirow{3}{*}{$\begin{array}{c}\text { Classification } \\
\text { designation }\end{array}$} & \multicolumn{4}{|c|}{$\begin{array}{l}\text { Maximum permitted number of particles per } \mathrm{m}^{3} \\
\text { equal to or greater than the tabulated size }\end{array}$} \\
\hline & & \multicolumn{2}{|c|}{ At Rest } & \multicolumn{2}{|c|}{ In Operation } \\
\hline & & $\geq 0.5 \mu \mathrm{m}$ & $\geq 5 \mu \mathrm{m}$ & $\geq 0.5 \mu \mathrm{m}$ & $\geq 5 \mu \mathrm{m}$ \\
\hline EU GGMP, Annex 1 & Grade A & 3520 & 20 & 3520 & 20 \\
\hline ISO 14644-1 & ISO 5 & 3520 & $\mathrm{a}$ & 3520 & $\mathrm{a}$ \\
\hline EU GGMP Annex 1 & Grade B & 3520 & 29 & 352000 & 2900 \\
\hline \multirow{2}{*}{ ISO $14644-1$} & ISO 5 & 3520 & a & - & - \\
\hline & ISO 7 & - & - & 352000 & 2930 \\
\hline EU GGMP Annex 1 & Grade C & 352000 & 2900 & 3520000 & 29000 \\
\hline \multirow[t]{2}{*}{ ISO 14644-1 } & $1 \mathrm{SO} 7^{b}$ & 352000 & 2930 & - & \\
\hline & ISO $8^{b}$ & 3520000 & 29300 & 3520000 & 29300 \\
\hline EU GGMP Annex 1 & Grade D & 3520000 & 29000 & $\begin{array}{c}\text { Not } \\
\text { defined }^{\mathrm{b}}\end{array}$ & $\begin{array}{c}\text { Not } \\
\text { defined }^{b}\end{array}$ \\
\hline ISO 14644-1 & ISO 8 & 3520000 & 29300 & - & - \\
\hline
\end{tabular}

Notes:

a. Sample collection limitations for both sizes of particles in low concentrations and sizes greater than $1 \mu \mathrm{m}$ make classification at this particle size inappropriate, due to potential particle losses in the system.

b. The 'in operation' concentrations for EU GGMP Grade D areas are not defined, and the user is expected to set their own limits. As the 'at rest' limits are typically easily attainable for 'in operation' conditions, the 'at rest' limits are often also applied to the 'in operation' state. 


\section{Appendix C: Table in ISO 14644-1:2015 used to obtain minimum number of samples in a cleanroom}

Table C1 Number of sampling locations required according to the size of the cleanroom given in ISO 14644-1.

\begin{tabular}{|c|c|}
\hline Area of cleanroom $\left(\mathrm{m}^{2}\right)$ less than or equal to & $\begin{array}{l}\text { Minimum number of sampling locations to be tested } \\
\qquad\left(N_{L}\right)\end{array}$ \\
\hline 2 & 1 \\
\hline 4 & 2 \\
\hline 6 & 3 \\
\hline 8 & 4 \\
\hline 10 & 5 \\
\hline 24 & 6 \\
\hline 28 & 7 \\
\hline 32 & 8 \\
\hline 36 & 9 \\
\hline 52 & 10 \\
\hline 56 & 11 \\
\hline 64 & 12 \\
\hline 68 & 13 \\
\hline 72 & 14 \\
\hline 76 & 15 \\
\hline 104 & 16 \\
\hline 108 & 17 \\
\hline 116 & 18 \\
\hline 148 & 19 \\
\hline 156 & 20 \\
\hline 192 & 21 \\
\hline 232 & 22 \\
\hline 276 & 23 \\
\hline 352 & 24 \\
\hline 436 & 25 \\
\hline 636 & 26 \\
\hline 1000 & 27 \\
\hline$>1000$ & See Note 3 \\
\hline \multicolumn{2}{|c|}{$\begin{array}{l}\text { Note } 1 \text { If the considered area falls between two values in the table, the greater of the two should be selected. } \\
\text { Note } 2 \text { In the case of unidirectional airflow, the area may be considered as the cross section of the moving air } \\
\text { perpendicular to the direction of the airflow. In all other cases the area may be considered as the horizontal } \\
\text { plan area of the cleanroom or clean zone. } \\
\text { Note } 3 \text { When the area of the cleanroom or clean zone is greater than } 1000 \mathrm{~m}^{2} \text {, apply the following formula to } \\
\text { determine the minimum number of locations required: } \\
N_{L}=27 \times\left[\frac{A}{1000}\right] \\
\text { Where } N_{L} \text { is the minimum number of sampling locations to be evaluated, rounded up to the next whole } \\
\text { number, and } A \text { is the area of the cleanroom in } \mathrm{m}^{2} \text {. }\end{array}$} \\
\hline
\end{tabular}

\section{Appendix D: Calculation of number of air sampling locations required for cleanroom classification}

To classify a cleanroom according to ISO 14644-1:2015, airborne particle sampling must be carried out across the cleanroom. The number of sampling locations is related to the surface area of the floor and given in Table A1 of ISO 14644-1 (reproduced in Appendix C of this article). ISO 14644-1 suggests that the floor area should be divided into equal sized areas where sampling is carried out. This is relatively simple to achieve in a cleanroom that is square or rectangle but difficult where the floor area is asymmetrical. However, ISO allows additional sections to be added to facilitate subdivision into equal sections. The ISO standard does not give information about how this sub-division can be carried out but the following method can be used.

1. Divide the asymmetric floor or base area of the cleanroom or clean zone into suitable sizes of rectangular sub-area. Start with the largest rectangle that can be accommodated and work towards the smallest.

2. Add together the floor surface areas $\left(\mathrm{m}^{2}\right)$ of the sub-areas to obtain the total floor area of the cleanroom.

3. Calculate the number of sampling sections in each sub-area using the following equation;

Number sections in sub-area $=\frac{\text { floor area of sub-area }}{\text { total floor area }} \times$ minimum no. sampling locations

Where, the 'minimum no. of sampling locations' is equal to the number of equal-sized sampling sections required for total floor area that is obtained from Table A1 of ISO 14644-1 (reproduced in Appendix C of this article).

These results should be rounded up to whole numbers (any number less than 1 should be assumed to be 1 ). Ensure that the total of these results is greater that the number required by ISO 14644-1.

4. Starting with the largest sub-area, divide its cleanroom floor area by the number of sampling sections required in its area. This will give the surface area of the sampling section and, taking account of the sampling requirements, the length and width of the sampling sections should be decided.

5. An example of the above method is given in the second part of this article ${ }^{3}$.

Using the formal risk assessment methods discussed in Appendix E of this article, the sampling locations within each section can be identified, and particle sampling carried out. 


\section{Appendix E: Use of risk assessment to select sampling locations}

Annex 1 of the EU GGMP (2008) requires the classification of a cleanroom or clean zone to be carried out according to the method given in ISO 14644-1. ISO 14644-1: 2015 recommends that the floor area of a cleanroom or clean zone is divided into sections, and airborne sampling carried out at locations representative of the conditions in the sections. However, the current expectations of the regulatory authorities is for sampling to be carried out where the risks from airborne contamination are highest. In clean air devices (EU GGMP Grade A, hereafter referred to as workstations), the chosen locations should be in proximity to critical surfaces, such as where product, components or product contacting surfaces, are exposed to airborne contamination. In cleanrooms that contain the clean air device, the sampling positions should be where the highest particle concentrations associated with personnel activity are located. In cleanrooms outside the aseptic processing room, the sampling should be carried out in representative locations without the need for a risk assessment.

Selection of sampling locations by risk assessment in critical workstation

Information about various risk assessment methods used in cleanrooms is available elsewhere (13). It is explained that the level of risk from contamination can be calculated by the following equation:

Risk $=$ Severity $\times$ Occurrence

Equation E.1

Severity; The importance, or seriousness, of an event. In the situation where the level of risk of airborne contamination to vulnerable surfaces, such as product, is required, the risk can be calculated by use of the following risk factors.

1. The likely particle airborne concentrations at a critical surface; However, this will not be known, but descriptors can be used as surrogates for the airborne concentration. These descriptors are (a) personal activity and, therefore, the dispersion rate of particles, and (b) the effectiveness of the ventilation system in reducing the airborne particle concentration.

2. The surface area of the critical surface that is exposed to airborne deposition.

It should be noted that only the airborne contamination dispersed from personnel is considered in this risk assessment, and not that from machinery or equipment. This will simplify the risk assessment and is consistent with the demonstrated fact (14) (15) that the most important contaminant in pharmaceutical cleanrooms is microbial, and not small inert particles. However, large sources of particles emitted from machines may influence the actual particle concentrations measured during classification and this should be considered when the sampling results are collected.

Occurrence; The frequency that the event occurs. In the case of airborne contamination, it is the time that the critical surface, such as product or product contacting surface, is exposed to airborne contamination.

An example of the descriptors of the risk factors, and the risk scores that can be assigned to the descriptors when assessing the risk of contamination, are given in Table E1.

Table E.1 Risk factors and scoring system for a risk assessment for critical workstation.

\begin{tabular}{|c|c|c|c|c|c|}
\hline $\begin{array}{c}\text { Personnel } \\
\text { activity }\end{array}$ & Score & Ventilation type & Score & $\begin{array}{c}\text { Surface } \\
\text { exposed }\end{array}$ & Time exposed \\
\hline Some activity & $\begin{array}{c}\text { Proportion of } \\
\text { manipulations } \\
\text { e.g. manipulations for 50\% } \\
\text { of the time gives a score } \\
\text { of 1.5 }\end{array}$ & $\begin{array}{c}\text { Open operation RABS } \\
\text { or } \\
\text { open access UDAF } \\
\text { workstation }\end{array}$ & 2 & Area $\left(\mathrm{cm}^{2}\right)$ & Time (mins) \\
\hline $\begin{array}{c}\text { Continuous } \\
\text { activity }\end{array}$ & 2 & Non-UDAF cleanroom & 3 & Area $\left(\mathrm{cm}^{2}\right)$ & Time (mins) \\
\hline
\end{tabular}

The level of risk at each location can then be obtained by the equation E.1;

$$
\begin{aligned}
\text { Risk } & =\text { Severity } x \text { Occurrence } \\
& =(\text { Personnel activity score } \times \text { Ventilation type score } x \text { Surface exposed }) \times \text { Time exposed }
\end{aligned}
$$

An example of the use of this method is given in Appendix B in the second article (3).

\section{Selection of sampling locations in the cleanroom containing a workstation}

For cleanrooms in which the clean air device is located and, therefore, critical surfaces are not directly exposed to airborne contamination, the sampling locations should be where the highest airborne concentrations of particles are found. As discussed previously, the emission of particles from machinery and equipment is likely to affect the particle concentration but only personnel need to be considered. An example of the use of this method is given in Appendix A in the second article.

\section{Cleanrooms adjacent to the aseptic processing room}

For lower Grades of cleanrooms that are adjacent to the aseptic processing room, samples should be taken at locations that are representative of conditions in each of the sections obtained by the procedure discussed in Appendix D. There is no need for a risk assessment. 